\title{
Roxane Gay's Hunger: A Memoir of (My) Body: A Fat Studies Approach
}

\author{
Md Tapu Rayhan', Assistant Professor \\ Nure Jannat ${ }^{3}$, Assistant Professor
}

Noakhali Science and Technology University, Noakhali, Bangladesh, $\mathrm{PhD}$

Researcher at Novosibirsk State University, Novosibirsk, Russia

Maruf Rahman ${ }^{4}$, Assistant Professor

Department of English, Noakhali Science and Technology University,

Noakhali, Bangladesh

Doi:10.19044/esj.2020.v16n26p108 URL:http://dx.doi.org/10.19044/esj.2020.v16n26p108

\begin{abstract}
There is much scholarly research about the impact of popular culture messages regarding fatness on people, but there is limited study on people's attitudes to those fat-shaming messages. Roxane Gay's Hunger: A Memoir of (My) Body is a memoir of her own body, traumatic journey, and fatness. This article looks through this memoir to find out Roxane Gay's attitude towards these messages in showing how people accept, react, and subvert these messages. This study will present this memoir as a manifestation of the prevailing negative representations of fat people in popular culture and how Gay, before and after being fat, responds to those fat-shaming messages produced by popular culture. This article, under the umbrella of Fat Studies, will discuss how Gay, because of her fatness, has been treated as other and marginalized in popular culture and how she presents herself as a proponent of Fat Studies. This research, discussing Gay's attitude to popular culture messages regarding fatness, will show how Gay, through this memoir, protests against fat-shaming messages and how she becomes the voice of every fat person.
\end{abstract}

Keywords: Fat studies, power and resistance, other, popular culture, fatshaming

${ }^{2}$ Corresponding Author

${ }^{3}$ First Author

${ }^{4}$ Second Author 


\section{Introduction}

Roxane Gay (born on October 15, 1974) is an American writer, professor, editor, and social commentator. Gay began writing essays in her teens, and her works are highly influenced by the gang rape caused by her first crush and his friends, which she had to go through when she was just a 12year-old girl. (Wikipedia, n.d.) In 2014, Gay published her debut novel, $A n$ Untamed State, which is about Mireille Duval Jameson, a Haitian-American woman who was kidnapped for ransom. This novel explores how the themes of race, privilege, sexual violence, family, and immigrant experiences are interlinked (Bass, 2014).

Roxane Gay has a knack for turning uncomfortable truths into necessary reading. The author, whose much-celebrated works Bad Feminist (2014) and Difficult Women (2017) made her a hero for millennial feminists, has never shied away from getting personal, but her latest project, a memoir called Hunger, goes deep. Gay unflinchingly guides readers through an exploration of pain, desire, and the realities of her life as an overweight woman, following a cataclysmic early trauma back to the root, and recording the reverberations that event has had on the rest of her life. (Okwodu, 2017)

Her novel Hunger: A Memoir of (My) Body was published in June 2017 which she says is a memoir of her own body, traumatic journey, and fatness where she shares her experiences to document "what it's like to live in a world that tried to discipline unruly bodies." (Bronis, 2016) In this book, she throws light upon the culture's punishing relationship with her fatness, bisexuality, and blackness. At the same time, she juxtaposes her relationship with her 'unruly body' with the influence of the American obsession with weight to criticize popular culture messages regarding obesity and the world's response to it. The current research focuses on this memoir in order to explore how Gay, telling her own story, encourages readers to reflect on the real experiences of fat individuals and feel the reality of living with fatness that has been defined as a problem by popular culture. Thus, this study will bring out how she, being a fat woman, presents a briskly frank depiction of several cases that are fraught with constant humiliations. This aims to help readers understand how a person reacts to popular culture messages in the social culture about their own and someone else's fat body.

\section{Statement of the Problem}

In our everyday lives, popular culture messages regarding body embed fat-shaming messages have a significant influence on people's attitude to fatness. These messages create fat hatred among individuals by presenting fat 
people as unhappy, unhealthy, defamed, and unnatural. The social culture is not ready to accept a fat body, as a result of which a fat person feels constrained in what (s)he is obliged to feel towards her/his own body and experiences complicated relationships surrounding her/his subjectivity. In short, popular culture is an extraordinarily "fat-aware" culture. In fact, the whole world is indifferent to the feelings and lifestyles of fat people. This indifference to fat people's reaction to these messages occupies a significant room in this study. Therefore, this article is intended to explore Hunger: A Memoir of (My) Body, where Roxane Gay shares her attitudes and reaction towards fatness before and after weight gain, to take an in-depth look at cultural artifacts, and to explore the reason and way fat people have become stigmatized in our everyday lives.

\section{Justification of the Study}

This study will add a new arena in the field of Fat Studies, which focuses mainly on the impact of popular culture messages regarding fatness on people, but less on how people respond to these messages. At the same time, this article can contribute to changing people's perception of body size because it reveals the inner pains and sufferings of fat people. Since this study focuses on Roxane Gay, who raises her voice through this memoir against the negative representation of fat people in popular culture, this study will embolden fat people and show them how to protest, resist, and subvert the fatshaming messages. On the other hand, in reading this article, readers who consider Roxane Gay as a feminist will begin to think of her as a proponent of Fat Studies.

\section{Research Methodology}

The qualitative research methodology is especially useful in analyzing human behaviors, relationships, and emotions in different intangible conditions, like questions over body weight.

Since this research aims to critically analyze the experience of Roxane Gay shared in Hunger: A Memoir of (My) Body, qualitative and descriptive research methodologies are used to serve the purpose. The close reading technique makes it possible to understand how Roxane Gay juxtaposes her experiences, relationships, attitudes, and Fat Studies to critique popular culture and fat-shaming messages. Moreover, taking Fat Studies as the theoretical framework and considering Roxane Gay as a proponent of Fat Studies, the purpose of this research is to interpret the attitude of people towards fatness critically. 


\section{Fat Studies}

In 1969, the foundation of NAAFA (National Association to Advance Fat Acceptance) by William Fabrey accelerated the emergence of the size acceptance movement. Later in the 1970s in Los Angeles, a group of fat women formed the Fat Underground as a reaction against discrimination of fat people in the medical sector. Two of their members, Judy Freespirit and Aldebaran, sought respect and equal rights for fat people by writing the Fat Liberation Manifesto (1983). NAAFA and the Fat Underground both used the word 'fat' instead of 'obese' or 'overweight.' (Rothblum, 2012)

At first glance, it seems that the words 'Fat,' 'Overweight,' and 'Obese' mean the same thing, although these words differ in connotative meanings. 'Overweight' and 'Obese" are medical terms that are usually used in medical science and defined by Body Mass Index (BMI), while 'Fat' is a cultural term that describes how a person looks, embracing the idea of both being overweight and obese.

This fat acceptance movement, later on, worked as a bottom line for Fat Studies, which became more multifaceted in the $21^{\text {st }}$ Century when Fat Studies tracks in the Popular Culture Association and the National Women's Studies Association. In 2006, The Smith College Conference and the Academy regarded Fat Studies as an academic discipline, and the New York Times focused on it in academia (Ellin, 2006). For this reason, Fat Studies is seen as an area of study that is based on Marxist theory, Feminist theory, Cultural Studies, and Sociology. It explores the intersections of not only social identities but also of politics, medicine, economics, society, and culture.

Fat Studies, with an extensive history and interdisciplinary literature, questions and criticizes traditional attitudes to fatness and draws upon the language, culture, and theory of civil rights, social justice, and social change. Fat Studies redefines the problem of fatness where, instead of the fat body, the main concern is cultural messages regarding fatphobia (Cooper, 2010). Studying people's attitudes toward body weight and appearance, Fat Studies speaks for the equality of all people in terms of weight. It considers weight as a human characteristic that varies widely in any population and aims at eliminating the negative aspects that social culture has regarding fatness. It is similar to academic disciplines that focus on race, ethnicity, gender, or age (Rothblum, 2012).

By glorifying thinness and presenting fatness as a social problem, popular culture messages create one kind of fat politics which arouses fat consciousness among the individuals. This fat consciousness challenges the pathologization of fat; emphasizes well-being over weight loss; rejects moral panic surrounding fat; questions dominant representations of the mutual exclusiveness of beauty, health, fitness and fat; celebrates diverse bodies; demands responsive healthcare; and critiques fat discrimination. This 
politicization of fat is taken up in a growing field of research called Fat Studies (Rothblum \& Solovay, The Fat Studies Reader, 2009). Fat studies emerged as a reaction against 'Fat Politics,' which 'traces the political consequences of an ideology that equates thinness with virtue and fat with vice. Indeed, this ideology drives both the science and culture of our national obsession with weight and weight control." (Campos, 2004) With this emergence, it very briskly became the center of research in literature, cultural studies, theatre, film and media studies, as well as the fine arts (Rothblum \& Solovay, The Fat Studies Reader, 2009).

Research in Fat Studies requires a deep study of Foucault's work because by exploring biological determinism and social constructions, Foucault's work discusses how the body is biologically and historically constructed and is thus relevant when considering the fat body. As among various Foucauldian theories, the theory of power and resistance from The History of Sexuality is critically analyzed in Fat Studies; it also demands to investigate the complex relationship between power and resistance as Foucault theorizes. In The History of Sexuality, Foucault says: "Where there is power, there is resistance, and yet, or rather consequently, this resistance is never in a position of exteriority in relation to power." (Foucault, 1978) Here, "what he seems to mean is this: because power is not coercive in the sense of direct threat of violence, it must be understood as an asymmetrical set of relations in which the existence of this multiplicity of nodal points or relations necessarily entails the possibility of resistance." (Malott \& Porfilio, 2011)

Fat Studies, along with the theory of power and resistance, helps this research to find out how Roxane Gay, a representative of fat people, responded to the oppressive power inherent in the social norms surrounding her fat body and how Roxane Gay, as a writer, in Hunger: A Memoir of (My) Body, unravels the stigmas surrounding the fat body by arguing against fat-shaming which creates discrimination against individuals and raises her voice for reducing fat shaming.

\section{Discussion and Findings}

The book begins with Gay declaring: "The story of my body is not a story of triumph. This is not a weight-loss memoir." (Gay, 2017, p. 11) She very boldly reveals that at her highest, she weighed 577 pounds at six feet, three inches tall, which, as she proceeds, is an 'unfathomable' number but the 'shameful truth' of her body. This truth is shameful not because she was ashamed of her body, but because of the judgmental advice of people, as well as their attitude towards her fat body: "This is a memoir of (my) body because, more often than not, stories of bodies like mine are ignored or dismissed or derided. People see bodies like mine and make their assumptions." (Gay, 2017, p. 11) 
These assumptions are the results of popular culture messages regarding body weight. Popular culture has a problem with the fatness of bodies. According to Gay, "Few areas of popular culture focus on obesity more than reality television, and that focus is glaring, harsh, often cruel." (Gay, 2017 , p. 87) Within our media-centric world, we are constrained by cultural productions of the fat body. This cultural production is pervasively hostile, where the fat people are not seen as normal human beings and, at the same time, instills traumatic feelings in them: "I am terrified of other people. I am terrified of the way they are likely to look at me, stare, talk about me, or say cruel things to me." (Gay, 2017, p. 120)

This feeling can be justified by what Amy Erdman Farrell writes about the differences between fat and thin body:

...by the late 19th-century fatness became a sign of a deficient body, one linked to the primitive, to the female, to the African, to the Hottentot. The thin body, in contrast, was one that was superior in quality: European-American, white, closest to the divine. (Farrell, 2011)

How people feel their own and other people's fat bodies are both regressive and progressive. How people respond to the popular culture messages they are exposed to regarding body weight is responsible for complex relationships they have with others due to fatness: "What's wrong with fat?... the answer to this basic question depends on how fatness is framed. And this has critical social implications." (Saguy, 2013) Gay, as a fat woman, faced the complexities and consequences of these negative cultural messages, but like a proponent of Fat Studies, she tried to resist and even subvert these fat-shaming messages:

There is a price to be paid for visibility, and there is even more of a price to be paid when you are hyper-visible. I am opinionated, and as a cultural critic, I share my opinions regularly. I am confident in my opinions and believe I have a right to share my point of view without apology. (Gay, 2017, p. 180)

She divides her life into two parts: "There is the before and the after. Before I gained weight. After I gained weight. Before I was raped. After I was raped." (Gay, 2017, p. 18) Like this, her attitudes towards fatness can be split into two parts: her attitude regarding a fat body, which was highly influenced by the popular culture messages, and her experiences of living with fatness.

Before she became fat, she studied the bodies of naked thin women from magazines that she found in Christopher's bedroom and realized: "He clearly found these women exciting, sexually attractive, and I knew, even then, 
that I was nothing like them." (Gay, 2017, p. 42) These too skinny bodies had been glorified there, which usually instigate man's desire for thin bodies. This very unattainable body type is considered as a standard of beauty in popular culture. In fact, this glorification of the super-thin body made Gay realize that thin female is more sexy and attractive.

For this reason, she tried to lose weight to be more attractive to Christopher: "Before this terrible thing happened, I had already started to lose my body." (Gay, 2017, p. 41) However, after being raped, as she started to hate her own body, she made the decision to go outside the 'norm' by becoming fat because those boys treated her 'like nothing,' she says starkly, 'so I became nothing.' Paradoxically, becoming nothing means becoming fat to make her unattractive and unwanted. She wanted to be fat, to be big, to be ignored by men, and to be safe. She considered a fat body as a desexualized as well as a protective state. She understood that to be fat was to be 'undesirable' to men, to be 'beneath their contempt.' She understood it because the messages, the knowledge that she received from culture and society, were all about accepting the thin body as superbly perfect and moral and the fat body as defective and immoral. Here, the cultural message that she received was: to be thin is to be attractive, and to be fat is to be unattractive. This message arouses a kind of hunger within her to be fat to be unwanted, which can never be satisfied. This hunger can be seen as an embodiment and the detrimental side-effects of popular culture's shaping of the body, for which she started operating within the framework of historically created systems of a 'good body' and a 'bad body.' Moreover, finally, she created a 'new body' that was shameful to her but gave her a sense of security, like 'a fortress, impermeable' that she desperately needed. She accepted the established concept of fatness and embraced a new fat body because, during this time, she was too young and knew 'nothing about anything.' Nevertheless, after she became fat, she voiced the experiences she went through as a fat woman to resist unreasonable standards for how a body should look by writing this memoir. She realized that living with fatness in a culture that is toxic to women and tries to discipline women's bodies is quite challenging. She feels that women need to feel comfortable in their bodies, without wanting to change anything about their bodies to find that comfort. She shares her experiences because she wants everyone to believe the worth of a human being does not depend on body weight.

The popular culture messages placed her body as a crime scene. People used to look at her body as something horrible, something that should be 'cordoned off and investigated.' In trying to get rid of her childhood trauma, she became fat and began to think that she was safe, but her body became a cage for her, in which she always struggled with the cultural perception of fatness. However, she broke her silence: 
Today, I am a fat woman. I don't think I am ugly. I don't hate myself in the way society would have me hate myself, but I do live in the world. I live in this body in this world, and I hate how the world all too often responds to this body. Intellectually, I recognize that I am not the problem. (Gay, 2017, p. 25)

She realized that thinness is a social currency because the social culture put her in an awkward situation where she felt that people around her only tolerated her out of pity. For society, maintaining the body is a kind of 'social responsibility.' From the classroom to cloth shop everywhere, she was treated as 'other' because of her fatness: "At the end of that first class, as the students filed out of the room, I wanted to collapse with relief because I had survived those fifty minutes of being fat in front of twenty-two eighteen- and nineteenyear-olds." (Gay, 2017, p. 77) She talks about how the cultural concept and its relationship to fatness destroy the inner strength of a fat person. Virgie Tovar describes the reason for this destruction by saying, "Because of the way fat people are positioned in our culture, people learn to fear becoming fat. They are afraid of discrimination and hatred." (Tovar, 2018)

Gay, as a fat woman, was outraged that people used to focus on her body as if her body became a matter of 'public record' and was always on display, which was unruly and frustrating, and it completely shut her down. She felt her body became a subject of 'public discourse.' This very unusual feeling was imposed upon her by the social and cultural construction. According to Virgie Tovar:

We as a culture have characterized being fat as an inherently bad thing when in reality, body size is meaningless and lacks the good or bad associations imposed by wider culture. We were not born thinking fat is bad and thin is good. We learn these things through an ongoing cultural education. (Tovar, 2018)

This cultural education categorizes a fat person as stupid, unaware, and delusional: "They forget that you are a person." (Gay, 2017, p. 84) In this memoir, though she describes her recovery journey, at the same time, she announces her position against the popular culture focusing on fatness.

Her experiences and feelings about her fat body are not linear; they are recursive. Before being fat, she accepted fat-shaming messages, but raised her voice to resist them after gaining weight: "Few areas of popular culture focus on obesity more than reality television, and that focus is glaring, harsh, often cruel." (Gay, 2017, p. 87)

Using the allusion of The Biggest Loser, which is a TV show about fat as an 'enemy' and a 'contagion,' she shows how the media, as a part of popular 
culture, is producing the positive and negative images of body weight. Addressing this TV show as 'weight-loss industrial complex' and 'anti-obesity propaganda,' she also criticizes the capitalistic approach to body weight. She hated this program but used to watch it to understand a world constructed by popular culture, which is not ready to accommodate the fat people. It was her way to subvert the fat-shaming messages to resist the stigmatization of her weight. She critically criticizes the TV programs by exposing her situation: "These commercials drive me crazy. They encourage self-loathing. They tell us, most of us, that we aren't good enough in our bodies as they are. They offer us the cruellest aspiration." (Gay, 2017, p. 92)

Fat Studies discusses strategies for resisting and subverting fatshaming messages to break the socio-cultural boundaries set on fat bodies. Each person has their way of resisting fat-shaming messages. Individual experiences of resistance are also different. Gay's experiences and feelings reveal how most of the fat people negotiate their resistance in popular culture of which they are embedded. To understand why they negotiate their resistance, it is essential to focus on what Foucault says. He posits that resistance must operate within the current power structures, which are all around us and which we are a part of, and that resistance manifests itself in different ways, at different times, and in different spaces (Foucault, 1978). Like this, Roxane Gay also has her own, like her recovery journey, which changes with times and places. To Gay, fat-shaming is real, constant, and instead pointed, which torments her internally. This inner pain gives her the power to resist them by delivering her message to the readers about how the popular culture messages influence the lifestyle of a person defining what is $\mathrm{good} / \mathrm{bad}$, what is (un)happiness, and how a person should respond to those messages. Gay's idea of this message can be linked with Tasha Fierce's idea: "Viewed as both unhealthy and unattractive, fat people are widely represented in popular culture and in interpersonal interactions as revolting as agents of abhorrence and disgust." (Fierce, 2010)

Gay's presentation of media is also another way how she resists media messages of fatness. She criticizes the media concept which glorifies the thinness by slandering fatness and considers the body of a celebrity as a commercial product which should have a unique thin look: "they are thinspiration - thin inspiration - a constant reminder of the distance between our bodies and what our bodies could be with the proper discipline." (Gay, 2017, p. 96)

Gay, to some extent, thinks like Virgie Tovar, who says,

There is no shortage of examples when it comes to the ways that fat people create cultural anxiety. It is no accident that fat people are underrepresented in the workplace, academia, and mass media. When we are visible, we are portrayed as 
unintelligent, lacking in grace or complexity, inherently amusing, abject, and either sexually insatiable or lacking any sexual desire. (Tovar, 2018)

For this, along with social media, she criticizes the working environment for fat people. She says that a fat woman in polite company is considered 'BBW (a big beautiful woman)' or 'SSBBW (super-sized big beautiful woman).' She is seen as 'round, curvy, chubby, rotund, pleasantly plump, "healthy," heavy ... buffalo, whale, elephant, two tons of fun, and a slew of names I don't have the heart to share." (Gay, 2017, p. 98)

Gay also talks about the foundation garments.

Although it is frequently argued that niche markets are currently replacing mass markets, and that consequently products are now tailored to meet the needs of specific targeted groups rather than those of a hypothetical average individual, the notion of an adaptable body remains central to the manufacturer's vision of the consumer. Clothes marketed specifically to larger women, for instance, still come in standard sizes with fixed proportions to which individual bodies must adapt. In fact, such clothing is usually marketed along with products such as "foundation garments," which are designed to facilitate this adaptation. (Rothblum \& Solovay, The Fat Studies Reader, 2009)

In an interview, when she was asked about the chapter of this book devoted to the difficulty of finding clothing, she replied,

It's infuriating. We all deserve to look cute and feel attractive.

What's so wonderful about fashion is that a good outfit makes you feel bold and sexy and beautiful, but we have to work so hard to find outfits that allow us to do that. Even the quality of the clothing [for plus sizes] isn't great; it's made poorly. (Okwodu, 2017)

In this chapter, she talks about the fashion trend which, as a part of popular culture, shows less concern for fat people and makes them unnoticed and unprivileged by representing them as shameful, insulting, marginalized, other, different, and excluded from the general society. Even most of the stores are designed for thin people, and there are 'a mere handful of stores' that can offer suitable dresses for fat people. For this reason, Gay expresses her hatred of this trend and culture of the fashion industry: "I am angry that the fashion industry is completely unwilling to design for a more diverse range of human bodies." (Gay, 2017, p. 124) The clothing of plus sizes in stores is usually 
stored in a separate corner as if these fabrics are intended for 'others' who are not worthy of being included in the general section. These cloths can be seen as a metaphor for fat people who are always highly visible but are treated as superbly invisible: "I am highly visible, but I am regularly treated like I am invisible. My body receives no respect or consideration or cares in public spaces. My body is treated as a public space." (Gay, 2017, p. 142)

Like her body, the plus size clothing is also both visible in its size and invisible. This (in)visibility can be justified by The Hyper(in)visible Fat Woman: Weight and Gender Discourse in Contemporary Society where Gailey says :

Fat presents an apparent paradox because it is visible and dissected publicly; in this respect, it is hypervisible. Fat is also marginalized and erased; in this respect, it is hyperinvisible.... To be hyper(in)visible means that a person is sometimes paid exceptional attention and is sometimes exceptionally overlooked, and it can happen simultaneously (7, original emphasis). (Gailey, 2014)

Furthermore, this (in)visibility causes fat people to receive fat-shaming messages even in the cloth stores, and these messages make them unhappy: "I've been that girl, too big for the clothes in the store, just trying to find something, anything, that fits, while also dealing with the commentary of someone else who means well but can't help but make pointed, insensitive comments." (Gay, 2017, p. 124) This made Gay understand that a fat person needs to pay the price for 'visibility' and sometimes needs to pay even more of a price when (s)he is 'hypervisible.' As a cultural critic, she considers it her responsibility to share her opinions regularly, and instead of living in this culture, she raises her voice by this piece of writing: "I wanted to burn the store down. I wanted to scream." (Gay, 2017, p. 125) This desire to protest against this culture of attitude towards fat people positions her voice as the voice of every fat person. This desire is described as Fat activists' objectives in BODIES OUT OF BOUNDS: "One of our objectives, then, is unmasking the fat body, rendering it visible and present, rather than invisible and absent: seen, rather than unsightly." (Brazie \& LeBesco, 2001)

Gay also speaks about doctors' and nurses' attitudes to fatness, which is also a concern of Fat Studies. Fat Studies have investigated the systematic marginalization of fat people in various fields, including healthcare (Pomeranz, 2008).

From her personal experience, she refers to the oath of doctors as the 'Hippocratic oath,' where they swear to abide by the 'code of ethics,' but in the case of an overweight patient, doctors seem fundamentally incapable of 
heeding their oath. At the same time, she criticizes the hospital management as well as hospital culture, which is not ready to treat the fat people:

There is the humiliation of simply being in the doctor's office, which is, all too often, ill-equipped for the obese body, despite all the public hysteria about obesity and health. Many scales cannot weigh patients who weigh over 350 pounds. Blood pressure cuffs are always too small, as are the threadbare hospital gowns. It is difficult to climb onto the exam table. It is difficult to lie back, to make myself vulnerable, to be splayed wide open. (Gay, 2017, p. 185)

Thus, in this book, she explores what it is like to live in a world that is not ready to accept fat people. To her, this is not that book where typically, we read about weight loss and triumph and a woman standing on the cover of the book in half her fat pants, but it feels challenging and exhausting, but necessary (Bronis, 2016).

It is challenging because it is a memoir of her own body, trauma, and weight. Nevertheless, it is necessary because here she attempts to change people's attitude in order to create a world ready to accept fat people as a human being by juxtaposing her relationship with her fat body. This relationship with her 'unruly body' in popular culture explores the reality of living in a fat body that is categorized as unnatural and problematic in society because "We live in a culture that tells the average American woman, dozens of times per day, that the shape of her body is the most important thing about her, and that she should be disgusted by it." (Campos, 2004)

Social culture never creates the opportunity to think about the need for fat people. In fact, it makes the fat people powerless to resist fat-shaming messages because resistance is closely related to power and occurs wherever there is power. Gay, as a fat woman, mightily complains explicitly about the shape of chairs that are not meant and designed to accommodate her. To her, 'chairs with arms' are intensely painful: "My thighs have been bruised, more often than not, for the past twenty-four years." (Gay, 2017, p. 139) This suffering can be seen as the result of the development of people's taste, which is highly dependent on the necessity created by popular culture. Usually,

Taste makes a virtue out of necessity. People develop preferences for what is available to them. The development of taste, which can be seen as a conscious manifestation of habitus, is embodied and deeply affects people's orientations to their bodies. (Shilling, 1993)

This development of taste makes the needs of fat people unavailable, which is one kind of unspoken humiliation. This taste orientates a fat body as 
something that should be neglected to be marginalized and creates a culture where people do not react by observing how fat people struggle to cope in a space that has no interest in accommodating them. In fact, the corner where the fat people are pushed to survive is inhospitable to them. For Gay, this is 'casual cruelty' or 'willful ignorance' instilled in them by popular culture.

By juxtaposing the relationship between 'fat and traveling,' she talks about many uncomfortable situations that make fat people think of themselves as untouchable. This untouchability is pervasive and brings numerous negative consequences in their life. It is never easy for any person to accept himself/herself as untouchable. This causes them to suffer from severe anxiety. This anxiety is the bitter result of culture because, according to Virgie Tovar, "The culture puts a lot of energy into forcing people to stay in that sad place of unquestioned fatphobia." (Tovar, 2018) Gay also found herself in this sad place: "I tried not to cry. Eventually, the agitated man was reseated elsewhere, and once the plane took off, I curled into the side of the plane and cried as invisibly, as silently, as I took off, I curled into the side of the plane and cried as invisibly, as silently, as I could." (Gay, 2017, p. 143) Gay's experience can be connected with the issues for which Southwest Airlines enforced a long-standing policy requiring large passengers to pay higher fares. "In June 2002, Southwest Airlines announced its intention to make passengers with hips spanning over seventeen inches pay for two airline seats. It claimed that the policy was created in response to customer complaints regarding fat passengers." (Huff, 2017)

Gay writes that although airlines prefer two tickets for a fat person, most airline employees have no idea how to deal with two boarding passes and an empty seat once the plane is fully loaded. This makes the journey more humiliating: "Even when you've bought two coach seats, travel is rife with humiliations." (Gay, 2017, p. 143) Moreover, these humiliations show us:

Our cultural context is rich in messages about what fat means for people, their worth, and their worthiness. Social attitudes are constantly informed by these messages. Popular culture and literature provide ample opportunities to reflect on the representation and construction of fatness and are especially active areas of fat studies scholarship. (Rothblum \& Solovay, The Fat Studies Reader, 2009)

Roxane Gay's experiences unlock the complexities of acceptance and/or resistance and how, as Foucault asserts, “...the points, knots, or focuses of resistance are spread over time and space at varying densities..." (Foucault, 1978). 


\section{Conclusion}

The results of this study reveal that Roxane Gay, living in a fat body, shows how fatness is framed by popular culture messages and sheds light on its critical social implications. The current study identifies Roxane Gay as a proponent of Fat Studies who writes against popular culture messages that create a sense of fat-shaming, which stigmatizes fat(ness) as the worst thing, presenting fat person as someone having no place in society, whose life is miserable, unhealthy, unnatural, devalued, subhuman, unworthy of living, and in dire need of improvement. At the same time, this study investigates Gay's presentation of how fat-shaming affects people's attitude to fatness and how popular culture frames our fat bodies as something that must be changed for a normal life. Thus, the findings of this research reveal that from the very beginning to the end, Gay remains very honest and bold about what she feels as a victim and believes in as a proponent of Fat Studies.

\section{References :}

1. (n.d.). Retrieved 06 25, 2020, from Wikipedia: https://en.wikipedia.org/wiki/Roxane_Gay

2. Bass, H. (2014). The New York Times. Retrieved 6 25, 2020, from https://www.nytimes.com/:

https://www.nytimes.com/2014/05/11/books/review/an-untamedstate-by-roxane-gay.html?_r=0

3. Brazie, J. E., \& LeBesco, K. (Eds.) (2001). Bodies out of Bounds: Fatness and Transgression. Berkeley and Los Angeles, London: University of California Press.

4. Bronis, L. (2016). elite daily. Retrieved 6 26, 2020, from https://www.elitedaily.com/:

https://www.elitedaily.com/women/roxane-gay-careeradvice/1362491

5. Campos, P. (2004). The Obesity Myth: Why America's Obsession with Weight is Hazardous to Your Health. Gotham Books.

6. Cooper, C. (2010). Fat Studies: Mapping the Field. Sociology Compass, 4(12), 1020-1034. doi: 10.1111/j.1751-9020.2010.00336.x

7. Ellin, A. (2006). The New York Times. Retrieved 7 28, 2020, from https://www.nytimes.com/:

https://www.nytimes.com/2006/11/26/fashion/26fat.html

8. Farrell, A. E. (2011). Fat shame: Stigma and the fat body in American culture. New York and London: New York University Press.

9. Fierce, T. (2010). bitchmedia. Retrieved 07 01, 2020, from https://www.bitchmedia.org/: https://www.bitchmedia.org/post/sizematters-your-big-fat-reading-list 
10. Foucault, M. (1978). The History of Sexuality. (R. Hurley, Trans.) New York: Pantheon Books.

11. Gailey, J. A. (2014). The Hyper(in)visible Fat Woman: Weight and Gender Discourse in Contemporary Society. New York: Palgrave Macmillan.

12. Gay, R. (2017). Hunger: A memoir of (my) body.

13. Huff, J. L. (2017). Access to the Sky: Airplane Seats and Fat Bodies as Contested Spaces. In A. Braithwaite, \& C. M. Orr, Everyday women's and gender studies: introductory concepts. New York, London: Routledge.

14. Malott, C. S., \& Porfilio, B. J. (Eds.) (2011). Critical Pedagogy in the TwentyFirst Century: A New Generation of Scholars. Charlotte, North Carolina: Information Age Pub.

15. Okwodu, J. (2017). Vogue. Retrieved 6 26, 2020, from https://www.vogue.com/: https://www.vogue.com/article/roxane-gayinterview-hunger-memoir

16. Pomeranz, J. L. (2008). A Historical Analysis of Public Health, the Law,. Obesity, 16(2). doi:10.1038/oby.2008.452

17. Rothblum, E. D. (2012). Why a Journal on Fat Studies? (F. Studies, Ed.) Fat Studies, 1(1), 3-5. doi:10.1080/21604851.2012.633469

18. Rothblum, E. D., \& Solovay, S. (2009). The Fat Studies Reader. New York: New York University Press.

19. Saguy, A. C. (2013). What's Wrong with Fat? New York: Oxford University Press.

20. Shilling, C. (1993). The Body and Social Theory. SAGE Publications Ltd.

21. Tovar, V. (2018). You have the right to remain fat. New York: Feminist Press. 